\title{
Piety in the sky
}

George Ellis

The Physics of Immortality: Modern Cosmology, God and the Resurrection of the Dead. By Frank J. Tipler. Doubleday: 1994. Pp. 528. \$24.95. To be published in the United Kingdom by Macmillan early next year.

THIS must be one of the most misleading books ever produced. It has a great air of authority and seems highly erudite, covering vast areas of knowledge in a polished way. There are perceptive comments on a wide range of topics throughout. Yet underneath this facade lies wishful fantasy and a total lack of intellectual rigour. It is a masterpiece of pseudoscience.

Frank Tipler deploys his astonishing breadth of knowledge to tackle in an apparently serious manner questions of vital importance. But his claims are fantastic: "This book is a description of the Omega Point Theory, which is a testable physical theory for an omnipresent, omniscient, omnipotent God who will one day in the far future resurrect every single one of us to live forever in an abode which is in all essentials the Judeo-Christian Heaven" (p. 1). All this is accomplished, he claims, on the basis of modern physics alone. He is an ultimate reductionist, who claims to perform one of the most astounding conjuring tricks of all time: his book, he says, shows that "theology is nothing but physical cosmology based on the assumption that life as a whole is immortal. . . Religion is now part of science" (pp. 338-339).

The secret of this trick lies in the consistent misuse of language combined with a blithe disregard for the experimental testability of his completely arbitrary series of assumptions. What one would have assumed was just an undergraduate joke is here presented as if it were a serious theory. But it fails all the criteria for serious consideration, despite being dressed up with spacetime diagrams, causal boundaries, Feynman diagrams, quantum wave packets and so on, presented in many highly technical appendices.

Tipler defines a 'living being' as an entity that codes information, with the information preserved by natural selection. He deduces from this (p. 125) that an automobile is alive - a reductio ad absurdum of his entire method of argumentation. His basic assumption is that life continues to exist right until the end of the existence of the Universe, which he further assumes collapses to a singularity in the future (a time-reversed 'big bang'). This ignores the fact that the indefinitely rising temperatures in such a Universe would dissociate not only molecules and atoms but even nuclei into their fundamental constituents, as a result of contin- ual bombardment by photons at supergiga-electronvolt energies. Both the reliable storage of complex biological information and its systematic and highly controlled hierarchical processing would be completely impossible in these circumstances - yet none of this deters Tipler from his fantasies, which involve total emulation of human beings in a hypothetical computer at an "Omega

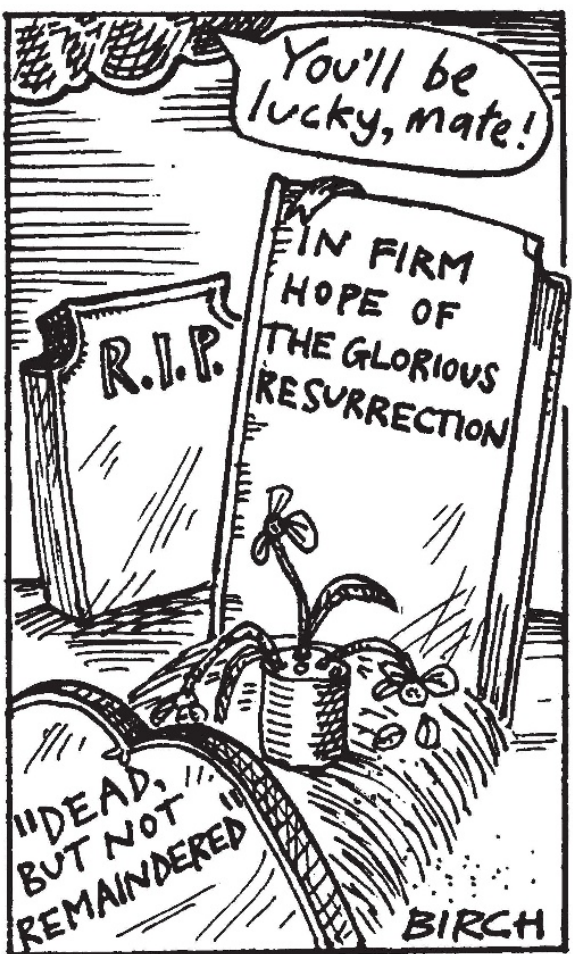

Point" (which if it were to exist would actually be outside spacetime, so nothing physical could happen there). This hypothetical process is what he calls "Resurrection". And we are supposed to believe that he has shown scientifically not only that this could happen, but that it necessarily will happen: "If any reader has lost a loved one, or is afraid of death, modern physics says: 'Be comforted, you and they shall live again"' (p. 1).

One cannot point out in a short review all the absurdities in this extraordinary edifice, which is the product of a fertile and creative imagination unhampered by the normal constrains of scientific or philosophical discipline. Tipler does not merely base his theory on highly improbable assumptions and make claims that cannot by any stretch of the imagination be tested by experiment or observation; he typically assigns the label 'God' to a mathematical construction that, while it might possibly be a good description of the causal boundary of the real Universe (it probably is not), certainly does not correspond in any serious sense to what the word 'God' is normally taken to refer to. $\mathrm{He}$ claims to prove - on the basis of physics alone - that this theoretical construction is a loving Being. This is indeed a totally new kind of physics. Out of kindness I refrain from quoting some of his claims about the nature of sex in his hypothetical "Heaven".

The real questions raised by this book are whether the author in fact believes what he has written, and why a respectable publisher has put it out. As regards the first, on page 305 he states: "I do not

believe in the Omega Point [because there is not yet any experimental evidence in its favour]". So the whole argument up to here is a game of some kind, an elaborate charade leading hopeful readers on in the naive belief that the author means what he says. For example, on page 1 he writes: "I shall show exactly why this power to resurrect which modern physics allows will actually exist in the far future, and why it will in fact be used" (my italics). Three hundred pages later he reveals that he himself does not believe the truth of the theory that leads to this statement. There is no reason why anybody else should believe it either: the theory does not and cannot tell us anything about whether resurrection of the dead - in the usual meaning of the phrase - will in fact take place.

On the second point, surely the explanation has to be that the publishers expect to make a lot of money from gullible members of the public who can be taken in by this kind of nonsense. They may be overestimating just how gullible people are. Or could it be that the publishers have fallen for this mirage? Is it perhaps they who are being taken in?

The Physics of Immortality does a considerable disservice to science by making incredible claims for what science can achieve - way beyond what in fact lies within its capabilities. Further, the book will make things much more difficult than before for those engaged in the debate about the relationship between science and theology, a debate that is gaining momentum. One should not make the mistake of believing that this book makes a worthwhile contribution to the discussion. It does not take seriously either science or theology - or indeed its readers.

George Ellis is in the Department of Applied Mathematics, University of Cape Town, Private Bag, Rondebosch 7700 , South Africa. 